\title{
A survey of the prescribing of selective serotonin reuptake inhibitors by psychiatrists
}

\author{
John Lawton and Prakash Naik
}

\begin{abstract}
Questionnaires were sent to 92 doctors asking them about aspects of their antidepressant prescribing; 72 returned them. Sixty had prescribed selective serotonin reuplake inhibltors (SSRis) in the previous year. The ratio of SSRis to all antidepressants prescribed in the previous year exceeded $40 \%$ in only eight doctors. Inability to tolerate and fallure to respond to established antidepressants were the most common indications for prescribing Sspis. Side effects and cost were the most common recsons deterring doctors from prescribing SSRls. SSRis being now products and doubls regarding their efilcacy were factors that were signilicantly more likely to deter 'doctors of other grades' than consultants from prescribing them. Fluoxetine and paroxetine were the most frequently prescribed SSPls.
\end{abstract}

Expenditure on antidepressants rose by $50 \%$ in 1992 (Drug and Therapeutics Bulletin, 1993b). A major factor leading to the increase has been the introduction of selective serotonin reuptake inhibitors (SSRIs). SSRIs are no more effective than traditionally used antidepressants but have a different spectrum of side effects and are considered safer in overdose.

With the introduction of the NHS reforms, financial aspects of drug therapy are receiving increasing attention. This sensitivity to drug costs has brought into focus cost-benefit and risk benefit analysis of antidepressants (Eccleston, 1993), and has led to greater importance being attached to the development of hospital formularies. At present there is a paucity of published information on aspects of the prescribing of SSRIs. These include the extent to which they are prescribed; factors encouraging and discouraging the prescribing of SSRIs; and the preferred choices of SSRIs. Therefore, there is a need for a study in these areas. On behalf of the Drug and Therapeutics Committee we surveyed the prescribing of SSRIs within the Nottingham Healthcare Unit which serves a population of 625000 .
A questionnnaire was designed to answer the following:

(a) the extent to which SSRIs were prescribed by doctors in the unit

(b) indications when SSRIs are preferred to more established antidepressants, such as a tricyclic

(c) factors deterring the prescribing of SSRIs

(d) the prescriber's choice of SSRI for inclusion in the hospital's formulary.

In June 1993, the questionnaire was distributed to all consultant psychiatrists and doctors of other grades, working in six of the seven clinical directorates of Nottingham Healthcare Unit. These included general psychiatry and psychotherapy, child and adolescent psychiatry, addiction and forensic psychiatry, health care of the elderly, rehabilitation and learning disabilities. The questionnaire was not sent to physical rehabilitation. A month later, a second questionnaire was sent to the nonresponders.

\section{Findings}

The questionnaire was distributed to 92 doctors. Seventy-two returned them, a response of $78 \%$. Thirty were from consultants and 42 from 'doctors of other grades'. There was no significant difference ( $\chi^{2}$ test) in the response rate between the groups.

Sixty-five doctors $(90 \%)$ had prescribed antidepressants. Those who had not prescribed them were working in psychotherapy or child psychiatry, specialities in which drugs are not usually prescribed. Sixty $(83 \%)$ had prescribed SSRIs in the previous year. Fig. 1 illustrates 


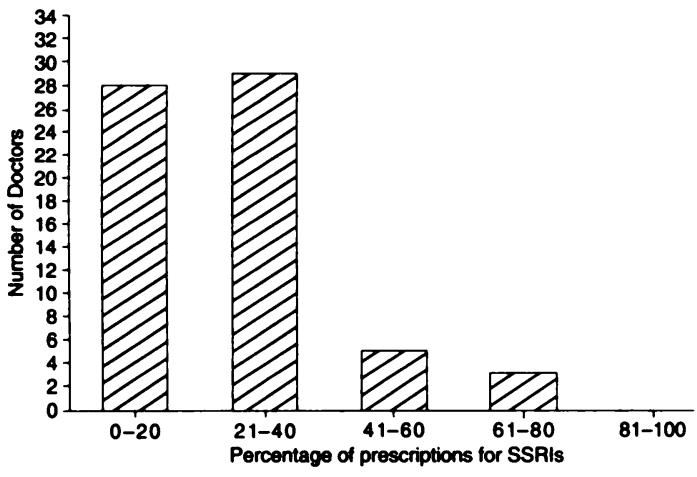

Fig. 1. Proportion of all antidepressants prescribed as SSRIs

the proportion of all antidepressants being prescribed as SSRIs by individual doctors in the previous year. The extent to which consultants and 'doctors of other grades' prescribed SSRIs was not significantly different $\left(\chi^{2}\right.$ test).

The indications for preferring to prescribe SSRIs are shown in Table 1 . If the other disorders' (obsessive-compulsive, eating and neurotic disorders) were considered as a group they would be the commonest indication for preferring an SSRI. 'Doctors of other grades' were more likely $(P<0.05)$ to prescribe SSRIs to avoid side effects of established antidepressants such as weight gain and sedation when compared to the consultants.

The frequency distribution of the factors deterring doctors from prescribing SSRIs are illustrated in Table 2. Only three doctors considered the SSRIs as no more effective than tricyclics as a deterrent. 'Doctors from other grades' were significantly more likely than consultants to consider SSRIs as new products and doubt over their efficacy in treating moderate and severe depressive illness, as deterrents in prescribing SSRIs.

Fluoxetine and paroxetine were the most frequent choices for inclusion in the hospital formulary, preferred by 39 and 13 doctors respectively. Sertraline and fluvoxamine were preferred by four and three doctors respectively. Three doctors did not want an SSRI to be included and three doctors did not state a preference.

\section{Comment}

Sixty doctors had prescribed SSRIs in the previous year. The ratio of SSRIs to all antidepressants prescribed exceeded $40 \%$ in only eight doctors. This compared with 57 doctors whose prescriptions for traditional antidepressants were in excess of $40 \%$ of their total antidepressant prescriptions. Thus traditional antidepressants represented most of the ant1depressant prescriptions.

SSRIs are no more effective and do not act faster than previous drug treatments for depression. Hence prescribers must consider other factors when choosing SSRIs. From our survey inability to tolerate, and failure to respond to, other antidepressants were the commonest indications for choosing an SSRI. This suggests that SSRIs are being used as second or third line agents. Around $40 \%$ of doctors mentioned that they used SSRIs when

Table 1. Indications when prescribing SSRIs is preferred to a more established antidepressant, such as a tricyclic

\begin{tabular}{llc}
\hline & $\begin{array}{l}\text { Consultants } \\
(n-30)\end{array}$ & $\begin{array}{c}\text { Other mecilical stanf } \\
(n-42)\end{array}$ \\
\hline Unable to tolerate other ADs & $13(43 \%)$ & $23(55 \%)$ \\
Failure to respond to other ADs & $12(40 \%)$ & $18(43 \%)$ \\
Other ADs best avolded, e.g. cardiovascular disease, glaucoma & $11(37 \%)$ & $18(43 \%)$ \\
High suicide risk or a history of Overdose & $9(30 \%)$ & $18(43 \%)$ \\
Avold side effects of other ADs, e.g. sedation, weight gain & $4(13 \%)$ & $14(33 \%)$ \\
Other disorders & & \\
Obsessive-compulsive disorder & $8(27 \%)$ & $11(26 \%)$ \\
Eating disorders & $6(20 \%)$ & $9(21 \%)$ \\
Neurotic disorders (e.g. phobia, panic) & $6(20 \%)$ & $2(5 \%)$ \\
\hline
\end{tabular}

ADs=Antidepressants

"Slgnificant $P<0.05$ 
Table 2. Factors deterring doctors from prescribing SSRIs

\begin{tabular}{llc}
\hline & $\begin{array}{l}\text { Consultants } \\
(\mathbf{n}-30)\end{array}$ & $\begin{array}{l}\text { Other medical staff } \\
(\mathbf{n}=\mathbf{4 2})\end{array}$ \\
\hline Side effects, e.g. insomnia, agitation, nausea & $15(50 \%)$ & $23(55 \%)$ \\
Cost & $13(44 \%)$ & $20(48 \%)$ \\
New product eg more experience needed & $4(13 \%)$ & $* 13(25 \%)$ \\
Doubts of efficacy in moderate to severe depression & $3(10 \%)$ & $\cdot 15(28 \%)$ \\
No more effective than a tricyclic & $1(3 \%)$ & $2(5 \%)$ \\
\hline
\end{tabular}

"Significant $P<0.05$

other antidepressants were best avoided (e.g. cardiovascular disease) or when there was a history of overdose or a high suicidal risk. This is surprising as these indications have been widely publicised.

Why are 'doctors of other grades' more likely to use SSRIs to avoid side effects of other antidepressants? Consultants may feel more confident in assessing when the benefits of using tricyclics outweigh their side effects. Perhaps, some consultants used the side effects of the drug as an advantage, e.g. a sedative antidepressant to aid sleep, a risk junior doctors may not be willing to take.

SSRIs were used in the treatment of obsessive-compulsive disorder, eating disorders, panic disorders, anxiety and phobic states. If these indications were considered as a group it was the commonest indication for choosing an SSRI. This is interesting as, with the exception of fluoxetine, licensed for use in bulimia nervosa at the time of our survey, none of the others has a product licence for these indications.

The adverse effects of traditional antidepressants appears to be the main reason for prescribing SSRIs yet adverse effects of SSRIs appear to be the main deterrent from prescribing them. Prescribers seem aware that SSRIs are not free from side effects but that they have a different side effect profile compared to the traditional antidepressants.

Cost was the second most common deterrent in prescribing SSRIs which are significantly more expensive than the older antidepressants. Doctors were aware of the cost but it was only one factor to be considered. It is reassuring in the current climate that cost should not be of overriding importance when choosing treatment.

Some doctors expressed doubts regarding the efficacy of SSRIs in moderate to severe depressive illness despite evidence of their effectiveness in these conditions. This may reflect their inherent belief in the value of traditional antidepressants or stem from their unsuccessful use of SSRIs as second or third line agents in patients who have not responded to previous antidepressant trials.

Many doctors considered the fact that SSRIs are new drugs as a deterring factor. They felt that their long-term safety had not been established. Recently extrapyramidal side effects and withdrawal symptoms have been reported with paroxetine and whether fluoxetine increases hostility and aggression remains an open question. Perhaps doctors are justified in being cautious.

Fluoxetine and paroxetine were the most popular SSRIs for inclusion in the formulary. But there are as yet insufficient comparative data to choose one SSRI as substantially better or worse than another (Pratt, 1993). Why then is there a difference in the popularity of individual drugs? Possible explanations include individual side effect profile, cost, experience based on their use and marketing strategies.

At present there is considerable debate as to whether SSRIs should be considered first or second line drugs in the treatment of depression. The Drug and Therapeutics Bulletin $(1993 a)$ do not recommend them as first line while Mackay (1993) suggests them as first line drugs and remarked that "tricyclics and their siblings may be heading for honourable retirement". Clear national guidelines are required.

\section{Acknowledgements}

We would like to thank members of the Drug and Therapeutics Committee, Nottingham 
Healthcare NHS Trust for allowing us to publish the results.

\section{References}

DRUG and Therapeutics BULETIN (1993a) Selective Serotonin Reuptake Inhibitors for Depression? Drug and Thera peutics Bulletin. 31, 57-8.

- (1993b) Prescribing costs. Drug and Therapeutics Bulletin, 31, 87.

ECCLESTON, D. (1993) The economic evaluation of antidepressant drug therapy. British Journal of Psychiatry. 163, 5-6.

MACKAY, A. V. P.(1993) Foreword. In A Review of the Selectwe Serotonin Reuptake Inhibitors 1993 (eds A Mackay. P. Pratt \& B. Leonard). Clwyd: Unicorn Health Communications Services.
PRATT, P. (1993) Pharmacokinetics and interactions of the SSRIs. In A Review of the Selective Serotonin Reuptake Inhibitors (eds A. Mackay, P. Pratt \& B. Leonard). Clwyd: Unicorn Health Communications Services.

*John Lawton, Clinical Services Pharmacist, Nottingham Healthcare NHS Trust, The Wells Road Centre, Wells Road, Nottingham NG3 3AA; and Prakash Naik, Consultant Psychiatrist, Lyndon Clinic, Hobs Meadow, Solihull, West Midlands B92 8PW

*Correspondence

\title{
The rise and fall of anti-psychiatry
}

\author{
Mervat Nasser
}

\begin{abstract}
A review is made of the anti-psychiatric movement through its major protagonists, Lacan, Laing, Cooper and Szasz. The ldeology was set to challenge the concept of mental illness and question the authortly of the poychiatrist and the need for mental health institutions. The anti-psychiatric movement recelved a lot of attention in the 1970s but is now considered to be of the past and of likely interest to the poychiattic historion. However, the impact of the movement on current poychiatric practice requires further re-examination and appraisal.
\end{abstract}

The anti-psychiatric movement grew in the realm of politics, particularly the politics of the left, which was considered at one time the main source of progressive ideas and possibly the only instrument against capitalist oppression. It gained its initial respect and glamour from its association with the prevailing existential philosophy at that time. The need to stengthen the relationship between psychiatry and philosophy is an old one and based on Kant's contention that judgements on matters of sanity should be the prerogative of the philosophical mind.

Despite these connections, the roots of the anti-psychiatric movement are undoubtedly to be found in the psychoanalytic tradition. The beginnings can be traced back to the writings of Jacques Lacan who was probably the first to glorify madness and regard it as the road to freedom. In a statement extracted from Propos sur la Causalité psychique (Paris, 1947) Lacan says, "madness is not an insult to liberty but follows liberty like its shadow". Lacan was also the first to launch an attack on established psychiatric thought and demand that psychoanalysis re-examine its concepts, with particular reference to explaining paranola. He thought that the psychotic experience could be psychoanalytically understood in the same way as psychoanalysis offers an explanation for neurosis. In his rebellion he undermined genetic disposition and dismissed the possibility of any organic pathology.

Lacan attempted to challenge accepted ways of understanding the psychotic experience and introduced to psychiatry what could be called a revised Freudian doctrine (Bowie, 1987). However, he is more likely to be remembered for the importance he gave to language in the field of psychoanalysis. His system strongly relates language to the unconscious, where he regards the spoken word as man's peculiar privilege and his tool to displace desire and attain freedom. In developing his linguistic 